\title{
Risk and Protective Factors for Fires, Burns, and Carbon Monoxide Poisoning in U.S. Households
}

\author{
Carol W. Runyan, PhD, Renee M. Johnson, MPH, Jingzhen Yang, MPH, Anna E. Waller, \\ ScD, David Perkis, MA, Stephen W. Marshall, PhD, Tamera Coyne-Beasley, MD, MPH, and \\ Kara S. McGee, MSPH, PA-C \\ Injury Prevention Research Center (Runyan, Johnson, Yang, Waller, Perkis, Marshall, Coyne- \\ Beasley, McGee), University of North Carolina, Chapel Hill, North Carolina; Departments of \\ Health Behavior and Health Education (Runyan, Johnson, Yang), and Epidemiology (Runyan, \\ Marshall), School of Public Health, University of North Carolina, Chapel Hill, North Carolina; and \\ Departments of Pediatrics (Runyan, Coyne-Beasley), Internal Medicine (Coyne-Beasley), and \\ Emergency Medicine (Waller), School of Medicine, University of North Carolina, Chapel Hill, \\ North Carolina
}

\section{Abstract}

Background-More needs to be known about the prevalence of risk and protective factors for fires, burns, and carbon monoxide poisoning in U.S. households.

\begin{abstract}
Methods-A random-digit-dial survey was conducted about home safety with 1003 respondents representing households in the continental United States. Descriptive statistics assess the prevalence of risk and protective factors for fires, burns, and carbon monoxide overall, and by demographic characteristics, household structure, region, and residential tenure. The data were weighted to adjust for nonresponse and to reflect the U.S. population.
\end{abstract}

\begin{abstract}
Results-Although most respondents reported having a smoke alarm (97\%), and 80\% reported having one on each level of their home, $<20 \%$ reported checking the alarm at least every 3 months. Seventy-one percent reported having a fire extinguisher, $29 \%$ had a carbon monoxide detector, and $51 \%$ of those living with at least one other person had a fire escape plan. Few could report the temperature of their hot water at the tap (9\%), or the setting on the hot water heater $(25 \%)$. Only $6 \%$ had an antiscald device.

Conclusions-Results suggest that there is much room for improvement regarding adoption of measures to prevent fires, burns, and carbon monoxide poisoning. Further investigations of the efficacy of carbon monoxide detectors, fire extinguishers, and escape plans, as well as effectiveness studies of fire and burn-prevention efforts are needed.
\end{abstract}

\section{Introduction}

Thermal and fire-related injuries, including burns from steam and hot liquids or objects, and injuries from flames, smoke, fumes, or carbon monoxide from a fire, are important public health problems. In 2001, there were 3796 deaths resulting from burns and fire-related injuries in the United States. ${ }^{1}$ The fire/burns death rate is higher among older adults, young

\footnotetext{
(C) 2005 American Journal of Preventive Medicine

Address correspondence and reprint requests to: Carol W. Runyan, PhD, University of North Carolina Injury Prevention Research Center, Bank of America Building, 137 East Franklin Street, Suite 500, Campus Box \#7505, Chapel Hill NC 27599-7505. carol_runyan@unc.edu.

No financial conflict of interest was reported by the authors of this report.
} 
children, those in the South, and among people living in manufactured housing, or who have relatively low incomes. ${ }^{1-5}$

An additional 498,507 persons experienced serious, but nonfatal, injuries. ${ }^{1,6-8}$ As with fire/ burns deaths, the nonfatal fire/burns injury rate is higher among young children and older adults. ${ }^{1,7,9}$ Children aged $<5$ years and adults aged $>60$ years compose about one fourth of all emergency department visits for burns and fire-related injuries, with scalds as a leading type of injury. ${ }^{1,7,10-12}$ Hot tap water is a major cause of scalds, resulting in $>3500$ emergency department visits each year. Scalds from hot tap water often are more severe than other types of scalds, because they tend to involve larger portions of the body surface. ${ }^{9}$

The home is the principal environment in which burns and fire-related injuries occur. ${ }^{13-20}$ From 1992 to 1999, 90\% of fatal fire/burn injuries, and 57\% of the injuries requiring emergency department visits took place in a residential environment. ${ }^{21}$ Tap water that is above $120^{\circ} \mathrm{F}$ represents a scald hazard for young children, older adults, and those with sensory deprivation. ${ }^{7,10,11,22}$ Stoves, ovens, space heaters, and other appliances are also important sources of residential fires and burns. ${ }^{18,23}$

In addition to being associated with residential fires, heating equipment and other appliances can result in carbon monoxide poisoning. ${ }^{24-26}$ Any time a carbon-based fuel (e.g., gas, oil, kerosene, propane, wood, or charcoal) is burned, carbon monoxide is released. If the appliance is not working properly, is being used incorrectly, or if there is insufficient ventilation, dangerous levels of carbon monoxide may be emitted. ${ }^{25-29}$ Each year in the United States, there are >200 residential nonfire, nonautomobile carbon monoxide poisoning deaths, two thirds of which are associated with heating equipment. ${ }^{13,26}$

Some injuries could be prevented through adoption of specific safety practices. Installation of smoke alarms on each level of a home is an effective strategy for preventing injuries and deaths due to residential fire, provided that they are properly maintained..$^{5-7,18,30-32}$ The Centers for Disease Control and Prevention (CDC) recommends that the batteries in batteryoperated smoke alarms be changed annually, and that smoke alarms be tested monthly to ensure that they are working properly. ${ }^{18,23}$ Installation of carbon monoxide detectors is also recommended in order to prevent carbon monoxide poisoning. ${ }^{24,25,33,34}$ Some evidence suggests that homes with carbon monoxide detectors may have fewer and less severe episodes of carbon monoxide poisoning. ${ }^{35-37}$ Maintaining tap water at $120^{\circ} \mathrm{F}$ is a successful strategy for reducing scalds. ${ }^{7,38-40}$ Water temperature can be lowered by adjusting the thermostat on the water heater or by an antiscald device at the tap. $., 9,10,12,41$ Although not as well documented in terms of efficacy, other safety recommendations include keeping a fire extinguisher in the kitchen for small fires, ${ }^{7,23}$ and having a fire escape plan for the household. $7,18,23,30$

The purpose of this study was to build on what is known regarding safety practices in U.S. households. Patterns of safety practices were examined among respondents representing a national sample of households, and variations investigated according to the presence of young children and/or older adults in the home, annual income, structural characteristics of the home, presence of carbon-releasing appliances, and region of residence.

\section{Methods}

Data for this investigation derive from the State of Home Safety in America (SOHS) study, which included a national telephone survey conducted with adults to assess the prevalence of home hazards and injury preventive practices. Respondents were required to be aged $\geq 18$ years and to have a role in making safety decisions for the household. Respondents were also required to speak English well enough to complete the interview, and to reside in a 
private residence. Those living in group facilities where decisions about safety practices are often not made at the individual level were excluded (i.e., prisons, nursing homes, assisted living facilities, barracks, and dormitories). Due to feasibility issues associated with distant time zones, only households throughout the 48 states in the continental United States (i.e., excluding Alaska and Hawaii) were included.

The SOHS survey was conducted for the University of North Carolina (UNC) Injury Prevention Research Center by the UNC Survey Research Unit (SRU). Using a list-assisted, random-digit-dial methodology, the SOHS survey was designed to provide a national probability sample of about 1000 private residences in the United States. The sampling frame was purchased from GENESYS Sampling Systems (Fort Washington PA). GENESYS develops sampling frames by routinely compiling area code-exchange combinations from the master file of telephone exchanges, which includes both published and unpublished numbers. Only those area code-exchange combinations serving residential numbers are retained in the GENESYS data file. In order to develop the sampling frame for the SOHS survey, a systematic sample of numbers was drawn from the GENESYS data file.

The data collection instrument was developed, pilot tested, and refined by the investigators in consultation with SRU. It was designed to elicit information about several issues important to home safety, including fires, burns, poisoning, and falls. Questions were designed to identify the presence of potential hazards in the home (e.g., gas appliances) as well as the presence of safety devices (e.g., carbon monoxide detectors, smoke alarms). Additional information was collected about (1) characteristics of respondents and individuals in their households (e.g., gender and ages of persons in the household, income level, home ownership status); (2) features of the home (e.g., type of structure, number of floors); and (3) geographic region.

Before commencement of data collection, letters describing the study were sent to all respondents in the sampling frame in order to give advance notice that someone would be calling their home. Interviewing took place from March 27, 2002 through June 13, 2002. The instrument had 92 items and an average administration time of 10 minutes. Data were collected using computer-assisted telephone interviewing technology (CATI), an interactive database system that presents each item to be read aloud by the interviewers on a computer monitor, and shows clarifying notes about administration of items. As with all CATIadministered surveys, interviewers entered respondents' answers into the computer during administration.

Telephone numbers were randomly selected for calling from the sampling frame. Trained staff at SRU interviewed whichever adult answered the telephone, provided that he/she met the study criteria. Interviewers made calls at different times of day and on different days of the week, with up to 20 callbacks made to each identified number. The advance letter, data collection instrument, and all administration procedures were reviewed and approved by the Institutional Review Board at the University of North Carolina School of Public Health.

Data from the interviews were downloaded into a data set for statistical analysis. Sample weights were computed in two stages in order to account for nonresponse and facilitate valid projections to U.S. households. In the first stage, a pseudo-selection probability weight was computed to account for differential probabilities of selection based on the presence of one, versus more than one, telephone lines per household, excluding those lines used exclusively for a home business, personal computer, or a fax machine. The second stage was a poststratification adjustment weighted to match March 2001 Current Population Survey data ${ }^{42}$ on presence of a child aged $<7$ years of age, presence of an adult aged $\geq 70$ years, and home ownership status. These variables were selected because they were expected to be 
correlated with survey measures of interest, and because they were characteristics of households rather than respondents, as households were the unit of analysis.

Data were analyzed using the SAS statistical package, version 8 (SAS Institute, Cary NC 2000). Descriptive statistics were generated to demonstrate the distribution of risk and protective factors for fires, burns, and poisonings within the households. Weighted point estimates of the proportion of individuals responding affirmatively to each variable were reported, with $95 \%$ confidence intervals, and the unweighted number of affirmative responses.

\section{Results}

\section{Survey Response and Representativeness}

Of the 1539 individuals identified as eligible to participate in the SOHS survey, interviews were completed with 1003 (65\%). There were 498 refusals, 38 incomplete interviews, and 1144 unanswered calls for which eligibility could not be determined (e.g., busy signal, no answer on repeated calls, answering machine). In addition, there were 1942 calls attempted to telephone lines determined to be no longer in service, used for dedicated fax lines, or at which respondents could not communicate in English. Assuming that all calls for which eligibility could not be determined had a distribution of eligibility equivalent to that of calls for which eligibility was determined, the response rate was $50 \%$. The rate was calculated using the American Association of Public Opinion Research's RR3 formula. ${ }^{43}$ The sample $(n=1003)$ was somewhat more affluent than the overall population, with fewer from the sample in the lowest income category. The prevalence of owner-occupied homes for those in the sample (68.0\%) was slightly lower than the prevalence of home ownership in the United States $(74.1 \%){ }^{44}$

\section{Smoke Alarms}

Almost all respondents (97\%) reported having at least one smoke alarm in the household, and $80 \%$ had smoke alarms on each level of their home. Households contained a variety of types of smoke alarms, with $65 \%$ reporting that their households had at least one batteryoperated alarm (25\% electric). Eighty-five percent of respondents indicated that they tested their smoke alarms at least once per year, and $20 \%$ indicated that they tested it at least every 3 months. Those with battery-operated smoke alarms in their homes, or with electric and battery-operated smoke alarms, were more likely to report checking their smoke alarms annually (86\%), as compared to those with electric smoke alarms only (78\%).

\section{Fire Extinguishers and Fire Escape Planning}

Nearly $69 \%$ of respondents reported having fire extinguishers, with the lowest proportion among those residing in apartments (41\%). Those with higher annual incomes were more likely to have fire extinguishers (Table 1). The examination of escape planning was restricted to those households with more than one resident $(n=814)$, because of the assumption that escape planning has a different character when one lives alone versus with others. Among this subset, $51 \%$ of respondents reported having discussed a fire escape plan with the other members of the household. Interestingly, fire escape planning was least common among households with residents aged $\geq 70$ (38\%) and among those living in apartments (31\%) (Table 1).

\section{Carbon Monoxide Detectors}

Only $29 \%$ of respondents reported the presence of a carbon monoxide detector in their homes and did not vary much by household demographics. Carbon monoxide detectors were 
most common in the Midwest (43\%), among those with an annual income of $>\$ 50,000$ (34\%), and among those living in owner-occupied homes (36\%) (Table 1).

\section{Hot Water Temperature}

Only one fourth of respondents indicated that they knew the temperature of the thermostat setting of their hot water heaters. Even fewer (9\%) indicated they knew the temperature of their hot water at the tap. Only $6 \%$ reported the presence of an antiscald device in their homes.

\section{Heating Sources and Gas Appliances}

The majority of respondents reported that gas was the primary heating source for their homes (54\%). Gas was also the most common primary heating source in each region except the South, in which electricity was the most common primary heating source (54\%). Although fuel oil as a primary heating source was rare in the South (3\%), Midwest (4\%), and West (3\%), it was much more common in the Northeast (37\%). Use of gas for heating or in appliances was most common among those with higher versus lower incomes (60\% vs $46 \%)$, those who lived in houses vs other types of dwellings (61\% vs 56\%), and among owner-occupied versus rented homes (58\% vs 52\%).

Thirty-one percent of respondents said that they used fireplaces or wood stoves, while $22 \%$ indicated that they used electric space heaters. Not surprisingly, use of wood stoves and fireplaces was most common among those with higher incomes (44\%), those in houses (39\%), those in duplexes or townhouses (26\%), and in owner-occupied homes (39\%). Use of kerosene heaters was rare overall (3\%), although use was higher among those in modular or manufactured homes (11\%). The presence of a fire extinguisher, smoke alarm, or fire escape plan did not vary substantially across household by the type of heating sources and presence of gas appliances in the home (Table 2). However, those with gas appliances, a fireplace or wood stove, or gas as primary heating source, were the most likely to report having carbon monoxide detectors (respectively, $35 \%, 36 \%$, and $38 \%$ ).

\section{Discussion}

The reported prevalence of smoke alarms in the homes of respondents (97\%) was slightly higher than the 1991 estimate by the CDC that $91 \%$ of households had a least one smoke alarm, ${ }^{30}$ which suggests that efforts to increase smoke alarm usage in the United States over the past decade have been successful. However, an estimated 3 million U.S. homes are still without smoke alarms, ${ }^{45}$ putting the residents at unnecessary risk in the event of a fire. In 2000 , there was no smoke alarm present in more than half of all residential fires. ${ }^{45}$

An additional issue is that, in many homes, smoke alarmsmay not be in working condition, and thus offer no benefit in the event of a fire. Thus, addressing the long-term maintenance of smoke alarms is a critically important, but possibly overlooked, aspect of fire prevention. ${ }^{46}$ In an intervention study in Oklahoma City, Mallonee et al. ${ }^{47}$ found that only $45 \%$ of installed smoke alarms were still functioning after 4 years. Similarly, a recent study in Britain showed that only one half of the smoke alarms installed during a randomized controlled trial were functioning 15 months later. ${ }^{48}$ Monthly checking of alarms is recommended, yet $<10 \%$ of respondents reported checking alarms with this frequency. Data from the Behavioral Risk Factor Surveillance System indicate that the statewide prevalence of checking smoke alarms monthly ranges from $31 \%$ in Colorado to $51 \%$ in Tennessee, with a median of $40 \% .{ }^{49}$ Rowland et al. ${ }^{48}$ found that households with ionizing smoke alarms using long-life lithium batteries were most likely to remain functioning, suggesting that lithium-powered alarms may be the preferred type to promote. 
The benefits of carbon monoxide detectors are less well established, although several studies suggest that they have beneficial effects. ${ }^{35-37}$ Lessons learned from the successful promotion of smoke alarms to almost universal coverage could be applied to the promotion of carbon monoxide detectors. However, further research is needed to determine the circumstances under which carbon monoxide detectors are helpful, and what types of detectors are appropriate to recommend or mandate.

Public health and fire officials have long endorsed fire escape planning, despite the lack of published data to support effectiveness. Earlier national estimates indicate that as many as $60 \%$ of households do report escape planning, yet the data revealed that only about half of those living with others had made a plan. ${ }^{30}$ It is possible that this discrepancy is a function of restricting this question to households in which more than one person lived. Other studies in specific populations have yielded a wide variation in the practice of determining a preplanned fire escape route, from $15.1 \%$ of households in inner-city Philadelphia to $97.2 \%$ of patients in a University of Kentucky geriatric clinic..$^{50-53}$

Respondents in the study reported a higher prevalence of having a fire extinguisher (69\%) compared to figures of $<60 \%$ in other studies. ${ }^{31,32,40,54}$ In addition, although no national estimate of carbon monoxide detector use could be found for comparison, the data indicate that far less than half of all households are equipped with such a detector; presence of detectors in homes where risks may be greater due to types of fuel used is also low. ${ }^{51,55,56}$ Further examination of the effectiveness of carbon monoxide detectors and fire extinguishers could help guide decisions by public health officials about the importance of continuing to recommend usage and, if proven effective, could guide development of efforts to increase usage.

The results on hot water temperatures are consistent with another national survey conducted by the CDC's National Center for Injury Prevention and Control, which revealed that only $23 \%$ of U.S. households with children aged $<18$ knew the temperature of their hot tap water. Of those who knew the temperature, only $9 \%$ reported that it was $<125^{\circ} \mathrm{F} .{ }^{31}$ In contrast, in a study of parents taking a child aged $<6$ to the pediatric emergency room, $65 \%$ of the 221 participants reported that their hot tap water was $\leq 120^{\circ} \mathrm{F} .{ }^{57}$ Studies in which the temperature of hot tap water was actually measured generally found higher prevalence of dangerous hot water temperatures. ${ }^{51,56,58-60}$ Only one study could be located that investigated the prevalence of installation of thermoregulation (i.e., "antiscald") devices on faucets. That study examined the residences of older adults and concluded that only 2 out of 39 total study participants had antiscald devices. ${ }^{12}$

The presence of safe hot water temperatures is hard to determine, and may need to be assessed via observational rather than survey methods. Numerous barriers to controlling temperature of hot water in one's home have been identified, ${ }^{61}$ and studies that assess these barriers could assist in planning targeted prevention programs. In addition, many parents of young children may simply be unaware of the danger of hot tap water to their children. ${ }^{60}$

This research was limited to homes meeting specific eligibility criteria, and does not represent all households in the United States, particularly those in which residents do not speak English and those outside the continental United States. At least one analysis suggests that homes with Latino immigrants may be at higher risk of fires and carbon monoxide poisoning, ${ }^{36}$ indicating the need for special safety promotion approaches with this group. In addition, the response rate of 50\%, while not unusual for a telephone survey, may have biased the findings if those who responded were either more or less likely to practice the safety behaviors in question. People who spend more time at home are both more likely to 
be available for telephone interviews and to experience higher exposure to home hazards. Unfortunately, this study does not assess exposure to the home environment.

Despite these limitations, the results point to the need to continue efforts to address fire, burn, and carbon monoxide safety issues. The high proportion of homes having smoke alarms is encouraging, although full compliance with recommendations of having alarms on multiple levels of the home and checked frequently is still in need of improvement. In addition, needs exist for understanding how best to address issues of carbon monoxide exposure and detection, and to examine further the development, use, and effectiveness of fire escape planning and use of fire extinguishers so as to develop appropriate public health interventions.

\section{Acknowledgments}

This work was funded by a contract from the Home Safety Council to the University of North Carolina Injury Prevention Research Center, with additional support from the National Center for Injury Prevention and Control (R49/CCR402444). We wish to thank Carla Black, MPH, Daniel Macklin, MD, MPH, and Ashley Bowers, MS, for their assistance. We also appreciate the helpful suggestions from the anonymous reviewers of this manuscript and the continued support from our colleagues at the Home Safety Council, Meri-K Appy, Patricia Adkins, and Sarah Miles.

\section{References}

1. National Center for Injury Prevention and Control. Web-based Injury Statistics Query and Reporting System (WISQARS). Centers for Disease Control and Prevention; 2003. Available at: www.cdc.gov/ncipc/wisqars

2. Quayle KS, Wick NA, Gnauck KA, Schootman M, Jaffe DM. Description of Missouri children who suffer burn injuries. Inj Prev. 2000; 6:255-258. [PubMed: 11144622]

3. Barillo DJ, Goode R. Fire fatality study: demographics of fire victims. Burns. 1996; 22:85-88. [PubMed: 8634135]

4. Istre GR, McCoy MA, Osborn J, B J, A B. Deaths and injuries from house fires. N Engl J Med. 2001; 344:1911-1916. [PubMed: 11419429]

5. Runyan CW, Bangdiwala SI, Linzer MA, Sacks JJ, Butts J. Risk factors for fatal residential fires. N Engl J Med. 1992; 327:859-863. [PubMed: 1508246]

6. McLoughlin E, Crawford JD. Burns. Pediatr Clin North Am. 1985; 32:75.

7. American Academy of Pediatrics. Fires and burns. In: Widome, MD., editor. Injury prevention and control for children and youth. 3rd ed.. Elk Grove Village IL: American Academy of Pediatrics, Committee on Injury and Poison Prevention; 1997. p. 233-267.

8. McLoughlin E, McGuire A. The causes, costs, and prevention of childhood injuries. Am J Dis Child. 1990; 144:677-683. [PubMed: 2346149]

9. Stockhausen AL, Katcher ML. Burn injury from products in the home: prevention and counseling. Wisc Med J. 2001; 100:39-44.

10. Feldman KW, Schaller RT, Feldman JA, McMillon M. Tap water scald burns in children. Pediatrics. 1977; 62:1-7. [PubMed: 683765]

11. Adams LE, Purdue GF, Hunt JL. Tap-water scald burns: awareness is not the problem. J Burn Care Rehabil. 1991; 12:91-95. [PubMed: 2022688]

12. Stone M, Evans AJ. The continuing risk of domestic hot water scalds to the elderly. Burns. 2000; 26:347-350. [PubMed: 10751702]

13. Runyan CW, Casteel C, Perkis DF, et al. Unintentional injuries in the home in the United States. Part I: mortality. Am J Prev Med. 2005; 28:73-79. [PubMed: 15626560]

14. Runyan CW, Perkis DF, Marshall SW, et al. Unintentional injuries in the home in the United States. Part II: Morbidity. Am J Prev Med. 2004; 28:80-87. [PubMed: 15626561]

15. Murphy, SL. National Vital Statistics Reports. Vol. 48. Hyattsville MD: National Vital Statistics System; 2000. Deaths: final data for 1998. 
16. Katcher ML. Burn injuries in Wisconsin: epidemiology and prevention. Wisc Med J. 1982; 81:2528.

17. Harwood B. Common products that cause uncommonly severe burn injuries. Natl Fire Protection Assoc J. 1996; 90:79-83.

18. Centers for Disease Control and Prevention. Deaths resulting from residential fires and the prevalence of smoke alarms-U.S., 1991-1995. MMWR Morb Mortal Wkly Rep. 1998; 47:803806. [PubMed: 9776167]

19. Centers for Disease Control and Prevention. Nonfatal residential fire-related injuries treated in emergency departments-United States, 2001. MMWR Morb Mortal Wkly Rep. 2003; 52:906908. [PubMed: 14508438]

20. Karter, MJ. Fire loss in the United States during 2002. Quincy MA: National Fire Protection Association, Fire Analysis and Research Division; 2003.

21. Runyan, C.; Casteel, C., editors. 2nd ed.. Washington DC: Home Safety Council; 2004. The state of home safety in America: facts about unintentional injuries in the home.

22. U.S. Consumer Product Safety Commission. tap water scalds, document \#5098. Available at: [Online] www.cpsc.gov/cpscpubs

23. Centers for Disease Control and Prevention. Deaths resulting from residential fires-United States, 1991. MMWR Morb Mortal Wkly Rep. 1994; 43:901-904. [PubMed: 7984140]

24. Centers for Disease Control and Prevention. Use of unvented residential heating appliancesUnited States, 1988-1994. MMWR Morb Mortal Wkly Rep. 1997; 46:1221-1224. [PubMed: 9427213]

25. Centers for Disease Control and Prevention. Unintentional carbon monoxide poisoning in residential settings-Connecticut, November 1993-March 1994. MMWR Morb Mortal Wkly Rep. 1995; 44:765-767. [PubMed: 7565559]

26. Ault, KL. Estimates of non-fire carbon monoxide poisoning deaths and injuries. Washington DC: U.S. Consumer Product Safety Commission; 1997.

27. Bizovi KE, B LJ, Hryhorczuk DO, Frateschi LJ. Night of the sirens: analysis of carbon monoxide detector experience in suburban Chicago. Ann Emerg Med. 1998; 31:737-740. [PubMed: 9624314]

28. Daley WR, Smith A, Paz-Argandona E, Malilay J, McGeehin M. An outbreak of carbon monoxide poisoning after a major ice storm in Maine. J Emerg Med. 2000; 18:87-93. [PubMed: 10645845]

29. Girman JR, Chang YL, Hayward SB, Liu KS. Causes of unintentional deaths from carbon monoxide poisonings in California. West J Med. 1998; 168:158-165. [PubMed: 9549414]

30. Harvey PA, Sacks JJ, Ryan GW, Bender PF. Residential smoke alarms and fire escape plans. Public Health Rep. 1998; 113:459-464. [PubMed: 9769771]

31. Mayer M, LeClere FB. Injury prevention measures in households with children in the United States, 1990. Adv Data. 1994; 250:1-16. [PubMed: 10137272]

32. Douglas MR, Mallonee S, Istre GR. Estimating the prevalence of homes with functioning smoke alarms: a comparison of telephone surveys and household survey results. Am J Public Health. 1999; 89:1112-1114. [PubMed: 10394329]

33. U.S. Consumer Product Safety Commission. Carbon monoxide detectors can save lives, \#5010. Available at: www.cpsc.gov.CPSCPUBS/PUBS/5010.html

34. Yoon SS, Macdonald SC, R G. Deaths from unintentional carbon monoxide poisoning and potential for prevention with carbon monoxide detectors. JAMA. 1998; 279:685-687. [PubMed: 9496987]

35. Krenzelok EP, Roth R, Full R. Carbon monoxide ... the silent killer with an audible solution. Am J Emerg Med. 1996; 15:484-486. [PubMed: 8765117]

36. Centers for Disease Control and Prevention. Use of carbon monoxide alarms of prevent poisonings during a power outage - North Carolina, December 2002. MMWR Morb Mortal Wkly Rep. 2004; 53:189-192. [PubMed: 15017373]

37. Clifton JC, Leikin JB, Hryhorczuk DO, Krenzelok EP. Surveillance for carbon monoxide poisoning using a national media clipping service. Am J Emerg Med. 2001; 19:106-108. [PubMed: 11239251] 
38. Macarthur C. Evaluation of Safe Kids Week 2001: prevention of scald and burn injuries in young children. Inj Prev. 2003; 9:112-116. [PubMed: 12810735]

39. Rivara FP. Burns: the importance of prevention. Inj Prev. 2000; 6:243-244. [PubMed: 11144619]

40. Liao CC, Rossignol AM. Landmarks in burn prevention. Burns. 2000; 26:422-434. [PubMed: 10812263]

41. Weaver AM, Himel HN, Edlich RF. Immersion scald burns: strategies for prevention. J Emerg Med. 1993; 11:397-402. [PubMed: 8228101]

42. U.S. Census Bureau. March 2001 Current Population Survey: annual demographic file. Washington DC: Bureau of Labor Statistics and Bureau of the Census; 2002.

43. American Association for Public Opinion Research. Standard definitions: final dispositions of case codes and outcome rates for surveys. Ann Arbor MI: American Association for Public Opinion Research; 2000.

44. Fields, J.; Casper, LM. America's families and living arrangements: March 2000. Washington DC: U.S. Census Bureau; 2000.

45. U.S. Fire Administration/National Fire Data Center. Residential structure fires in 2000: topical fire research series. Vol. vol. 3. Emmitsburg MD: U.S. Department of Homeland Security, Federal Emergency Management Agency; 2004.

46. Chen LH, Gielen AC, McDonald EM. Validity of self-reported home safety practices. Inj Prev. 2003; 9:73-75. [PubMed: 12642564]

47. Mallonee S, Istre GR, Rosenberg M, et al. Surveillance and prevention of residential-fire injuries. N Engl J Med. 1996; 335:27-31. [PubMed: 8637539]

48. Rowland D, DiGuiseppi C, Roberts I, et al. Prevalence of working smoke alarms in local authority inner city housing: randomised controlled trial. BMJ. 2002; 325:998-1001. [PubMed: 12411356]

49. Bolen JC, Sacks JJ, Bland SD. Injury prevention behaviors: a report card for the nation, 1995. Prev Med. 1999; 29:195-201. [PubMed: 10479607]

50. Polivka BJ, Ryan-Wenger N. Health promotion and injury prevention behaviors of elementary school children. Pediatr Nurs. 1999; 25:127-134. [PubMed: 10532009]

51. Schwarz DF, Grisso JA, Miles C, Holmes JH, Sutton RL. An injury prevention program in an urban African-American community. Am J Public Health. 1993; 83:675-680. [PubMed: 8484447]

52. Stiles NJ, Bratcher D, Ramsbottom-Lucier M, Hunter CG. Evaluating fire safety in older persons through home visits. J Ky Med Assoc. 2001; 99:105-110. [PubMed: 11268784]

53. Thompson R, Summers S, Rampey-Dobbs R, Mani MM, Hiebert JH, Schneider S. The effect of instruction on burn prevention in eighth-grade students in preparation for babysitting. J Burn Care Rehabil. 1992; 13:482-486. [PubMed: 1429823]

54. National Center for Injury Prevention and Control. CDC injury research agenda. Atlanta GA: Centers for Disease Control and Prevention; 2002.

55. Santer LJ, Stocking CB. Safety practices and living conditions of low-income urban families. Pediatrics. 1991; 88:1112-1118. [PubMed: 1956727]

56. Mobley C, Sugarman JR, Deam C, Giles L. Prevalence of risk factors for residential fire and burn injuries in an American Indian community. Public Health Rep. 1994; 109:702-705. [PubMed: 7938394]

57. Coyne-Beasley T, McGee KS, Johnson RM, Bordley WC. The association of handgun storage practices with safety consciousness. Arch Pediatr Adolesc Med. 2002; 156:763-768. [PubMed: 12144365]

58. Gielen AC, Wilson MEH, Faden RR, Wissow L, Harvilchuck JD. In-home injury prevention practices for infants and toddlers: the role of parental beliefs, barriers, and housing quality. Health Educ Q. 1995; 22:85-95. [PubMed: 7721603]

59. Sharp GB, Carter MA. Prevalence of smoke detectors and safe tap-water temperatures among welfare recipients in Memphis, Tennessee. J Community Health. 1992; 17:351-365. [PubMed: 1293141]

60. Pichoff BE, Schydlower M, Stephenson SR. Children at risk for accidental burns from hot tap water. Tex Med Nov. 1994; 90:54-58. 
61. Jaye C, Simpson JC, Langley JD. Barriers to safe hot tap water: results from a national study of New Zealand plumbers. Inj Prev Dec. 2001; 7:302-306. 
Table 1

Prevalence of preventive practices for residential fires, burns, and carbon monoxide poisoning, by selected characteristics, United States, 2002 (unweighted $n=1003)^{a}$

\begin{tabular}{|c|c|c|c|c|c|}
\hline & \multirow[b]{2}{*}{$\begin{array}{r}\text { Unweighted } \\
n \text { of } \\
\text { respondents }\end{array}$} & \multicolumn{4}{|c|}{ Proportion of households with: } \\
\hline & & $\begin{array}{l}\text { Fire } \\
\text { extinguisher } \\
\text { Weighted } \\
\text { percentage } \\
(95 \% \mathrm{CI})\end{array}$ & $\begin{array}{l}\text { Smoke alarm } \\
\text { Weighted } \\
\text { percentage } \\
(95 \% \mathrm{CI})\end{array}$ & $\begin{array}{l}\text { Fire escape } \\
\text { plan } b \\
\text { Weighted } \\
\text { percentage } \\
(95 \% \text { CI })\end{array}$ & $\begin{array}{l}\text { Carbon-monoxide } \\
\text { detector } \\
\text { Weighted } \\
\text { percentage } \\
(\mathbf{9 5 \%} \mathrm{CI})\end{array}$ \\
\hline \multicolumn{6}{|l|}{ Annual household income ${ }^{c}$} \\
\hline$<\$ 50,000$ & 438 & $59.6(54.9-64.4)$ & $95.4(93.4-97.3)$ & $43.1(37.5-48.7)$ & $23.1(19.1-27.1)$ \\
\hline$\geq \$ 50,000$ & 428 & $78.9(74.8-83.0)$ & $97.9(96.5-99.3)$ & $56.8(51.6-61.9)$ & $34.2(29.6-38.9)$ \\
\hline \multicolumn{6}{|l|}{ Household composition } \\
\hline Child aged $\leq 6$ years & 197 & $69.7(63.0-76.5)$ & $94.6(91.1-98.1)$ & $54.5(47.3-61.7)$ & $30.9(24.2-37.5)$ \\
\hline Adult aged $\geq 70$ years & 148 & $67.3(59.4-75.2)$ & $97.5(95.0-99.9)$ & $37.8(27.8-47.7)$ & $28.0(20.7-35.4)$ \\
\hline $\begin{array}{l}\text { No children aged } \leq 6 \text { years or adults } \geq 70 \\
\text { years }\end{array}$ & 514 & $73.2(69.1-77.2)$ & $96.9(95.4-98.4)$ & $52.8(48.4-57.3)$ & $31.5(27.4-35.6)$ \\
\hline \multicolumn{6}{|l|}{ Structure of home } \\
\hline House & 698 & $76.2(72.9-79.5)$ & $96.4(94.9-97.8)$ & $55.4(51.4-59.5)$ & $34.9(31.2-38.5)$ \\
\hline Modular/manufactured & 67 & $72.9(62.0-83.8)$ & $99.1(97.5-100.0)$ & $49.0(35.9-62.2)$ & $16.3(7.1-35.6)$ \\
\hline Apartment/apartment-type & 164 & $41.2(33.5-48.8)$ & $95.8(92.9-98.8)$ & $31.0(21.4-40.7)$ & $16.5(10.8-22.2)$ \\
\hline Duplex/townhouse & 74 & $72.2(61.7-82.6)$ & $99.4(98.1-100.0)$ & $39.6(25.8-53.3)$ & $20.5(11.3-29.7)$ \\
\hline \multicolumn{6}{|l|}{ Residential tenure } \\
\hline Owner-occupied property & 747 & $78.1(75.1-81.2)$ & $97.4(96.3-98.6)$ & $56.7(52.7-60.7)$ & $35.7(32.2-39.2)$ \\
\hline Rental property & 243 & $47.2(40.8-53.6)$ & $95.2(92.7-97.8)$ & $34.7(27.5-41.9)$ & $13.8(9.4-18.2)$ \\
\hline \multicolumn{6}{|l|}{ Region of residence ${ }^{d}$} \\
\hline Northeast & 211 & $66.9(60.1-73.7)$ & $97.9(96.0-99.8)$ & $50.7(42.8-58.6)$ & $36.3(29.7-42.9)$ \\
\hline Midwest & 247 & $72.3(66.4-78.2)$ & $98.6(97.0-100.0)$ & $56.6(49.6-63.6)$ & $43.2(36.9-49.6)$ \\
\hline South & 348 & $68.3(63.1-73.4)$ & 94.7 (92.3-97.0) & $48.5(42.5-54.6)$ & $20.7(16.4-25.0)$ \\
\hline West & 197 & $66.0(59.0-72.9)$ & $96.4(93.7-99.1)$ & $46.6(38.6-54.6)$ & $17.4(11.9-22.9)$ \\
\hline Total & 1003 & $68.5(65.5-71.5)$ & 96.7 (95.5-97.8) & $50.6(47.1-54.6)$ & $28.8(25.9-31.6)$ \\
\hline
\end{tabular}

${ }^{a}$ Percentages weighted by presence of multiple phone lines, any person aged $\leq 6$ years, any person aged $\geq 70$ years, and tenure (owner-occupied vs rental) in the overall population of U.S. households, excluding Alaska and Hawaii.

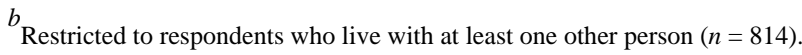

${ }^{c}$ Eighty-six percent of respondents reported their incomes.

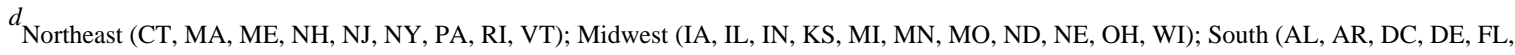
FA, KY, LA, MD, MS, NC, OK, SC, TN, TX, VA, WV); West (AZ, CA, CO, ID, MT, NM, NV, OR, UT, WA, WY).

$\mathrm{CI}$, confidence interval. 
Table 2

Prevalence of preventive practices for residential fires, burns, and carbon monoxide poisoning, by type of heating sources and appliances, United States, 2002 (unweighted $n=1003)^{a}$

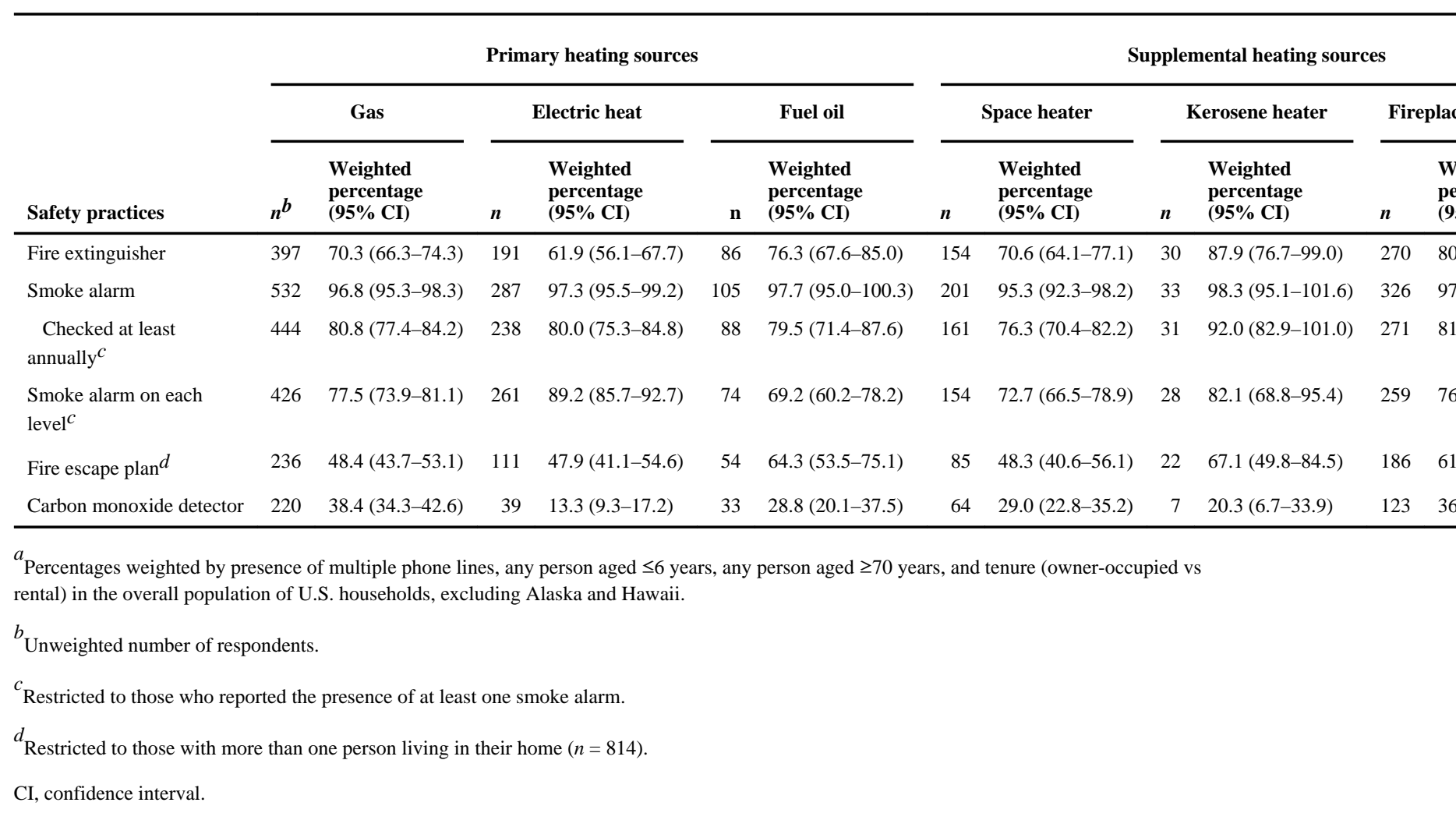

